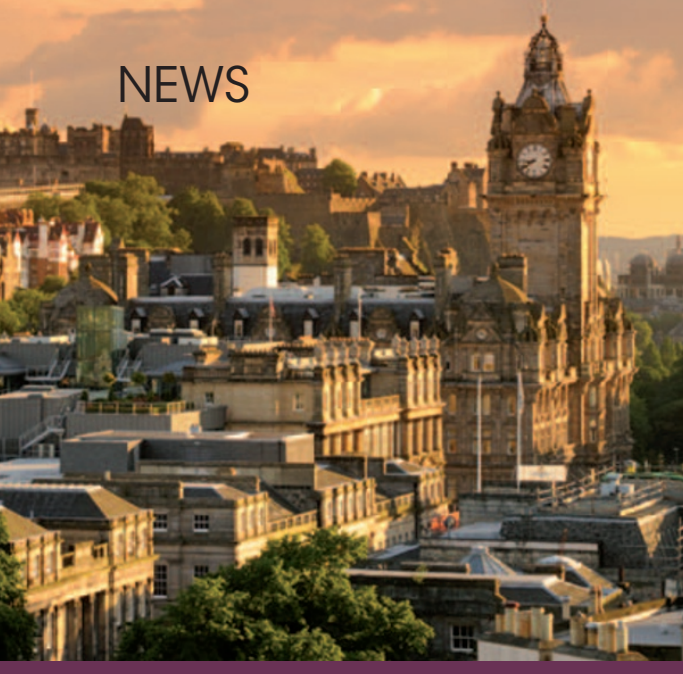

SECOND SCOTTISH SYMPOSIUM FOR DCP CPD

The second Dental Care Professional (DCP) Symposium in Edinburgh will take place on 20 April 2012 and is open to 180 delegates. The first ever Symposium held by NHS Education for Scotland SE took place on 9 September 2011 at Boroughmuir Rugby Club in Edinburgh. Although NHS Education for Scotland (NES) had been providing continuing professional development (CPD) across Scotland for many years, it had encountered some barriers such as the cost implications for DCPs, the time required out of the workplace and the lack of knowledge among DCPs regarding participating and recording CPD in line with General Dental Council (GDC) registration.

The aim of the Symposium for DCPs was to cover a diverse range of topics, including core $\mathrm{CPD}$ topics, and provide six hours of verifiable $\mathrm{CPD}$ for 100 delegates.

The first Symposium was fully booked with a waiting list poised for any last minute cancellations. 'There was a wide range of DCPs including hygienists, therapists, dental technicians, dental nurses and admin support from general practice, community and hospital services in the South East', said Sara Marwick, CPD Tutor and Dental Nurse Tutor SE at Edinburgh Postgraduate Dental Institute, who organises the symposiums.

Some of the speakers at the September event stayed on after their session to give extra support to delegates and all delegates were given the opportunity to evaluate the day.

'I would love to attend more of these symposiums as I felt they were excellent in terms of value for money, relevance and quality. [...] The speakers were knowledgeable and delivery was very entertaining,' commented one delegate.

The second Symposium will be at a centrally located venue in Edinburgh.

Visit www.portal.scot.nhs.uk for more information and for other NES courses.

\title{
JAM-PACKED PROGRAMME FOR ADAM IN HARROGATE
}

The Association of Dental Administrators and Managers (ADAM), formerly the British Dental Practice Managers' Association (BDPMA), is thrilled to be hosting a conference after an absence of four years. The ADAM Conference will be held on 18-19 May in Harrogate and will also feature the first ever ADAM awards.

The ADAM Conference, in partnership with the Medical and Dental Defence Union of Scotland (MDDUS), is called 'The Nuts and Bolts of Practice Management' and will take place at the four-star Majestic Hotel.

A diverse programme has been developed for delegates, featuring high calibre guest speakers imparting wisdom on a range of topics close to the hearts and minds of practice managers and administrators, such as customer service, performance management, financial control and assertiveness skills. A mock disciplinary hearing will also be held on the Friday afternoon.

The ADAM Conference Dinner and Awards Ceremony will crown the event, with awards finalists and their supporters invited to dress up and applaud the winners of Practice Manager of the Year, Administrator of the Year and Treatment Coordinator of the Year.

'There aren't many events in the dental calendar designed with only practice managers and administrators in mind, so we are hoping this will be popular,' said Jill Taylor, ADAM's President. 'We have developed a jam-packed programme that will leave delegates buzzing with ideas and a desire to get back to the practice to implement a host of new initiatives.'

To download a conference brochure visit www.adam-aspire.co.uk.

ENCOURAGE KIDS TO BRUSH WITH JACKSON

\section{Rosie's Playtime, a company based in Edinburgh and set up by a husband and wife team, has launched a smartphone application (app) called Brush with Jackson. In the app, Jackson Rabbit brushes his teeth alongside children in the bathroom or at the kitchen sink. With supervision, children can use Jackson as a timer to brush for the recommended 2-3 minutes, twice a day, and have fun while doing it. \\ Using Jackson in this way means parents will be able to buy their child a high quality toothbrush and by using Jackson morning}

and night help the child develop the healthy habit of keeping their teeth clean and shiny like Jackson.

As well as addressing the need for toothbrushing in children, Jackson will repeat what is said to him, giggle, squeal, wink, twitch his nose and play his kazoo.

Brush with Jackson is available from the Apple iTunes App store costing $£ 1.49$ for the iPhone/iPod touch version. A version for iPad will be released soon costing $£ 2.49$.

www.rosiesplaytime.com

Follow on Twitter @Rosiesplaytime.

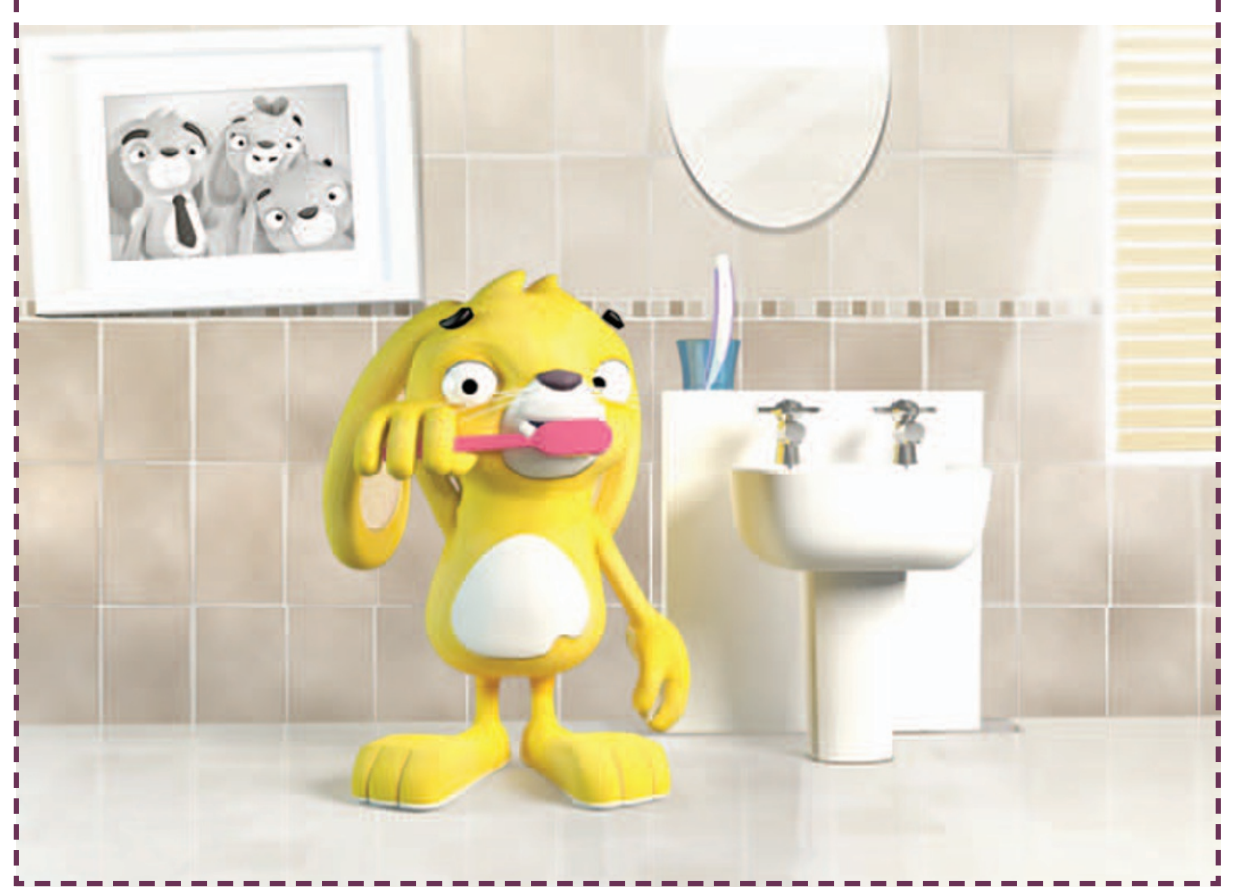

